\title{
ESTADO DE SITIO; GESTO DE COLECCIONAR: CONVERSANDO CON RAFAEL TORMO CUENCA
}

\author{
Izaskun Etxebarria Madinabeitia \\ Universidad Politécnica de Valencia (UPV). Dpto. Escultura. Doctorando
}

\section{Resumen}

A partir de la conversación con el artista valenciano Rafael Tormo Cuenca surge una reflexión en torno a nuestra relación con el mundo en este momento en el que nos relacionamos a través de dispositivos tecnológicos y pareciera que nuestro entorno social físico ha quedado abandonado. Esta comunicación parte de un proyecto de comisariado que consiste en dar forma a ciertas ideas que rodean esta hipótesis y las vincula al pensamiento contemporáneo, con la figura central de Walter Benjamin visto desde la mirada de Hito Steyerl y el propio artista. El acto de coleccionar, la incidencia de la tecnología y otras formas de economía son analizadas aquí desde el fenómeno de las grandes exposiciones universales en contraposición a la práctica artística en sí misma.

\section{Palabras Clave: PRÁCTICA ARTÍSTICA; PENSAMIENTO CRÍTICO; EXPO- SICIONES UNIVERSALES; COMISARIADO; COLECCIO- NISMO}

\section{STATE OF SIEGE; GESTURE OF COLLECTING: A CONVERSATION WITH RAFAEL TORMO CUENCA}

\section{Abstract}

From the conversation with the valencian artist Rafael Tormo Cuenca comes a reflection on our relationship with the world at this time in which we interact through technological devices and it seems that our physical social environment has been abandoned. This communication begins from a curatorial project consisting in giving shape to ideas surrounding this hypothesis and links them to contemporary thought, with the central figure of Walter Benjamin seen from the perspective of Hito Steyerl and the artist himself. The act of collecting, the impact of technology and other forms of economy are analyzed here from the phenomenon of the great universal exhibitions as opposed to artistic practice itself.

Keywords: ARTISTIC PRACTICE; CRITICAL THINKING; UNIVERSAL EXHIBITIONS; CURATING; COLLECTING

\footnotetext{
Echevarría Madinabeitia, Izaskun. 2016. "Estado de sitio; gesto de coleccionar: Conversando con Rafael Tormo Cuenca". AusArt 4(2): 155167 DOI: 10.1387/ausart.17093
}

\section{AUSART}




\section{INTRODUCCIÓN}

Este relato narra el proceso de trabajo de "Implosió Impugnada 22. Estado de sitio; gesto de coleccionar" del artista Rafael Tormo Cuenca que se desarrolla a lo largo de dos años con la producción de vídeos, textos y la instalación en sala de las obras en tres espacios diferentes: Antiguo Ayuntamiento de Alberic (Valencia, noviembre 2014), Sala Portalea de Eibar (Guipúzcoa, marzo 2015) y octubre Centre de Cultura Contemporània (Valencia, mayo 2016).

"El proyecto gira en torno a los que coleccionan y no sobre los objetos coleccionados. Este trabajo se cuestiona cómo nos relacionamos hoy día con los objetos del presente y del pasado que comparten escena contemporánea con nosotros. Al mismo tiempo, trata de explorar la potencia de estas cosas y cómo afectan a la cultura que vivimos; ayudándonos, a veces, a repensar y criticar aquello que nos rodea, o a hegemonizar, más si cabe, aquello que nos condiciona para estar en el mundo de forma más liberada. Comenzar a escuchar a aquellos que recogen, etiquetan, ordenan o patrimonializan estos objetos es un primer paso para pensar en común el poder de transformación social que tienen y no sólo aceptar el hecho de seguir con su aislamiento museístico." (R. Tormo Cuenca, comunicación personal, 8 agosto 2014)

El 8 de agosto 2014, el artista y yo mantuvimos una conversación. Me recomendó dos textos que estaba leyendo y constituían el marco de referencia de lo que tenía entre manos para partir de un lugar común: El lenguaje de las cosas de Hito Steyerl y Ni folklóriko ni masivo. ¿Qué es lo popular? de Néstor García Canclini.

Mi idea inicial fue crear un texto general que enlazara el estilo ligero de la conversación con un análisis más profundo como material de sala. Pensé hacer una transcripción de nuestra conversación para construir una buena conversación porque rescatar esa idea de "lo popular" en nuestra propia práctica implicaba elaborar un texto ágil. Lo que no pensé es que nuestra conversación llegase a crecer como una planta veloz por todos los rincones del pensamiento.

El objetivo fue contextualizar la práctica artística que se estaba desarrollando a partir de los ensayos y la conversación para anclarlos finalmente en un marco general. Al artista le pareció interesante dejar que todo fuera mutando, incluso nuestra posición en esta historia. Pero todo empezó antes, con una serie de pasajes descriptivos que se sitúan en un tiempo y un lugar concretos - a veces presentes, otros pasados y otros futuros - y parten de mi propia 
experiencia; porque es inevitable escapar a nuestro propio cuerpo y como cuerpo, a su tránsito.

\section{PREÁMBULO}

Nuestro barco no salía del puerto debido al temporal, así que decidimos pasar el día en el pueblo y volvimos a recorrer la misma calle estrecha que subía por la empinada colina. La casualidad nos llevó de frente a un portal que habíamos pasado de largo, una especie de museo antropológico local. Como en casi todos estos sitios, en él podían verse herramientas para las labores del campo y de la mar, utensilios de cocina y del hogar como planchas antiguas, ollas y perolas, una máquina de coser, diferentes tipos de tijeras, motores antiguos y un sin fin de objetos más o menos reconocibles. Precisamente en este ejemplo, se veía claramente cómo el objeto había quedado disociado de su función y no sabíamos si aquellas tijeras servirían para limpiar pescado o para esquilar ovejas ni si los cencerros serían para las cabras que vimos en el monte.

Evidentemente, la antropología hacía un desesperado intento por preservar el saber antiguo con aquella colección de objetos cuyos usos quedaban un tanto indefinidos; pero ¿de qué servía en realidad preservar aquellas cosas, para quién eran? Y, sobretodo, ¿quién se encargaba de coleccionarlas y clasificarlas? A nosotros, como turistas nos daba una imagen de un pasado bastante común, ya que a pesar de separarnos todo un mar, compartíamos una sabiduría sobre la tierra y la vida cotidiana.

“La 55a Bienal de Venecia se tituló II Palazzo Enciclopedico. Este título estaba inspirado en la obra del artista autodidacta italo-americano Marino Auriti, que en 1955 registró su diseño del Palazzo Enciclopedico en la oficina de patentes de Estados Unidos, un museo imaginario cuya función sería albergar el conocimiento acumulado en todo el mundo, conteniendo los mayores descubrimientos de la especie humana, desde la rueda hasta el satélite. Atrincherado en su garaje en mitad del campo en Pensilvania, Auriti trabajó en su creación durante años, y construyó una maqueta de un edificio de 136 pisos que se alzaría 700 metros y ocuparía 16 manzanas en Washington, D.C. Su plan jamás fue Ilevado a cabo, evidentemente, pero el sueño de un conocimiento 
universal que abarcase todo, se presenta inesperadamente a lo largo de la historia del arte y la humanidad, como algo, que excéntricos como Auriti, comparten con otros muchos artistas, escritores, científicos, o autoproclamados profetas que han intentado, a menudo en vano, confeccionar una imagen del mundo que capture su variedad y riqueza infinitas."

(Gioni 2013, 18 [Traducción personal])

Massimiliano Gioni, comisario de la Bienal, resumía la muestra aludiendo a "esas cosmologías personales - con su delirio omnisciente-como un fenómeno que arrojaba luz sobre la constante de reconciliar el sujeto con el universo, lo subjetivo con lo colectivo, lo específico con lo general y lo individual con la cultura de su tiempo" $(2013,18)$. La Bienal de 2013 giró en torno a las diversas formas de transmitir, tipificar o clasificar el saber a partir de los más dispares actores y sus obras. Pocos meses después, Rafael Tormo Cuenca se preguntaba rabiosamente cuál era esa relación que tenemos con los objetos y por consiguiente, con el mundo, ahora que todo parecía haberse virtualizado.

\section{PRIMERA PARTE. EL ACTO DE COLECCIONAR}

"La lengua nos indica de manera inequívoca que la memoria no es un instrumento para conocer el pasado, sino sólo su medio. La memoria es el medio de lo vivido, al igual que la tierra viene a ser el medio en que las viejas ciudades están sepultadas. Y quien quiera acercarse a lo que es su pasado sepultado tiene que comportarse como un hombre que excava. $Y$, sobre todo, no ha de tener reparo en volver una y otra vez al mismo asunto, en irlo revolviendo $y$ esparciendo tal como se revuelve y se esparce la tierra."

(Benjamin [1927-1940] 2010, 350)

\section{¿Cómo surge este proyecto?}

La idea inicial fue hacer un proyecto en homenaje a Mossèn Antoni, un coleccionista muy conocido dentro de la ciudad, pero sobre todo en la comarca, que había hecho una colección de cerámica, libros y esculturas sacras. Estas colecciones se diseminaron a su muerte. El 12 de mayo de 
1998 se editó un libro inventariando toda su colección. Una colección con miles de altibajos.

¿Crees que se debería retomar ese proyecto en algún momento?

Posiblemente. Creo que su figura fue fundamental en que hubiera tantos coleccionistas hoy día en Alberic. Habría que trabajar sobre su figura especialmente, pero cuando te acercas a algo, de pronto descubres que hay otras muchas cosas. Así que, en vez de focalizarlo hacia la figura principal, intenté hacerlo de una forma más coral y contemporánea. O sea, hablar de cómo nos relacionamos con los objetos, más que sobre qué colecciones tienen, que es más la función de un museo. Yo me dediqué a buscar transversalidades, tangencias y posicionamientos a la hora de coleccionar. Por eso, evité mostrar ningún objeto de este tipo de sus colecciones, porque todas son colecciones que datan entre el siglo XV y el siglo XX. Preferí hacer algo que no tuviera nada que ver con los trabajos que tienen ellos ya hechos. Aunque ellos son la base fundamental del proyecto.

Parece que trates aquí, de manera transversal, el cambio de una sociedad de consumo de objetos físicos a una sociedad de consumo de servicios y bienes inmateriales. Aunque el hecho de coleccionar objetos parezca algo residual o menos relevante para las generaciones futuras, ¿porqué sigue existiendo el coleccionismo?

"Implosió impugnada 22" consta de tres piezas. La primera, es videográfica y expone las motivaciones, las colecciones y la necesidad del hecho de compartir. La segunda, es una instalación sonora generada a partir de un breve taller con miembros del IES Consuelo Aranda de Alberic donde trabajé a partir de la relación afectiva y utilitaria de algunos de los objetos más importantes de sus vidas. Y la tercera, los libros, expone a los coleccionistas de una manera fragmentada y coleccionada para posibilitar otro tipo de experiencia relacional con ellos.

"El hechizo más hondo de que dispone el coleccionista consiste en encerrar al interior de un círculo mágico el objeto individual, mientras el postrer escalofrío (ser adquirido como mercancía), lo atraviesa y lo va petrificando. Todo lo recordado, como lo pensado y lo sabido se convierte en zócalo, pasa a ser el marco, el pedestal, más aún, el sello de su posesión. (...) Coleccionar que es forma del recuerdo remitida a la praxis, es la más decisiva de las varias manifestaciones profanas correspondientes a la 'cercanía'."

(Benjamin 1927-1940, 340) 
"Els llibres" muestra una serie de imágenes que nos producen una experiencia estética. Podríamos empezar a hablar de un lenguaje plástico específico. No somos muy conscientes de lo que estamos viendo aún. Es el propio retrato despiezado y compilado de los coleccionistas, un procedimiento que se utiliza en talleres de impresión para coleccionar las páginas que configurarán una encuadernación.

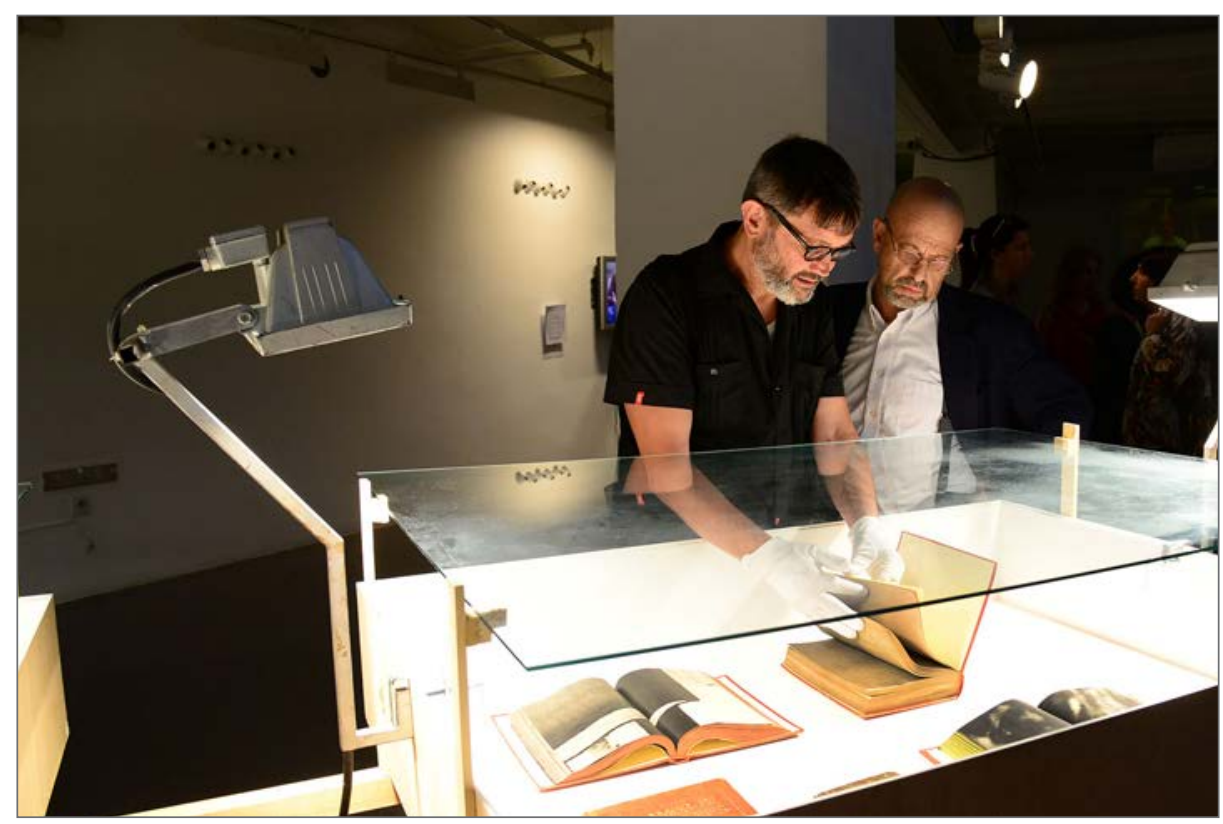

Imagen 1. ELS LLIBRES. Octubre Centre de Cultura Contemporània. València. Mayo 2016

\section{SEGUNDA PARTE. CAPITALISMO $\neq$ VIDA POÉTICA}

"Hoy en día, tanto los gobiernos como el mundo empresarial abrazan la creatividad, la innovación, la autenticidad y la idiosincrasia. El emprendedor 'progresista' ha comprendido los beneficios de abrir paso al espíritu artístico para su negocio posfordista, y el político abraza las artes con miras a una ciudad atractiva creativa que se sostenga a sí misma en la competición global de 'lugares donde hay que estar'. En otras palabras, al cabo de 20 años, el arte —o, cuanto menos, 'lo artístico'- ha pasado de los márgenes de 
la sociedad a su mismo núcleo. O, como afirma el filósofo italiano Paolo Virno, haciendo eco al escritor alemán Hans Enznesberger: el arte se ha diluido en la sociedad como una aspirina efervescente en un vaso de agua."

(Gielen 2008, 11)

Recibí esta idea con cierta melancolía, porque me parecía demasiado real y trágica. Esta crisis económica nos ha enseñado que el capitalismo, por su naturaleza, necesita expandirse para sobrevivir porque sus crisis son sistémicas. El colonialismo que llevó a los europeos a colonizar todos los rincones del planeta en busca de mano de obra y materias primas baratas fue -en particular durante el último tercio del s.XIX - en busca, también, de nuevos mercados donde dar salida a sus excedentes de producción.

En esa época surgen las grandes exposiciones universales como motor económico y estímulo al consumo, pero al mismo tiempo como tentativa para mostrar a los trabajadores europeos cómo era el mundo, ese mundo que ellos mismos estaban construyendo con su esfuerzo como actores de la revolución industrial. El interés por el conocimiento y la cultura, así como muchos museos surgen en esta misma época como forma de entender enraizada en el conocimiento enciclopédico, la clasificación y el estudio de objetos.

En la 55 $5^{\mathrm{a}}$ Bienal, el Pabellón de Grecia mostraba una obra audiovisual sobre el valor de las cosas tremendamente interesante: "History Zero" de Stefanos Tsivopoulos. La idea se contaba a través de tres relatos dispuestos de manera simultánea y complementarios entre sí: uno protagonizado por una coleccionista de arte; otro por un artista conceptual; y el tercero por un inmigrante africano que recogía chatarra. Las tres escenas se desarrollaban en Atenas y nos hablaban del valor de las cosas; de lo anecdótico del valor del dinero.

Según Pascal Gielen (2008, 71), "por un lado está la economía informal, que se basa en la confianza y la amistad, el reconocimiento mutuo y el respeto. Dentro de éste, el intercambio basado en el principio de reciprocidad se encuentra dentro de las posibilidades. Luego existe una economía simbólica, (...). Si una obra tiene una gran cantidad de capital simbólico, puede ser utilizado para adquirir otras obras con un valor simbólico importante. (...) Por último, se hace presente una economía monetaria: si una obra no es donada, siempre se va a tener que comprar. Lo interesante aquí es la interacción que se produce entre estas economías informales, simbólicas y monetarias". 
En el sistema económico actual la cultura se mide en términos de producción mercantil. Néstor García Canclini (1987) reflexiona sobre la noción de "lo popular" y diferencia dos disciplinas: la antropología y los estudios sobre comunicación. En el primer caso, lo popular queda vinculado al folklore y de esta manera a lo territorial e histórico, y en un sentido a lo oral, lo tradicional y lo manual. Pero los estudios antropológicos hasta el momento han venido aplicando una descontextualización de lo global que acaba por recontextualizarlo bajo un orden interno y crea así, una referencialidad propia. Los procesos de industrialización, las migraciones y la urbanización de grandes masas sociales han provocado una acción homogeneizadora de la industria cultural. Pero lo popular atraviesa lo territorial y se sitúa en un lugar mucho más impreciso, aunque evidente.

\section{TERCERA PARTE. CÓMO NOS RELACIONAMOS CON EL MUNDO}

"Se dice Historia desde que hay conciencia histórica, que esencialmente se caracteriza por ser capaz de considerar su propio tiempo como una época histórica, y por aplicar el nombre del género literario Historia a los sucesos supuestamente reales; de modo que en ella se hace historia, con una fe implícita en un Destino de la Humanidad."

(García Calvo 1983, 14)

Agustín García Calvo habla de ese ámbito de lo real que hablabas tú. ¿Dónde está, qué es lo que está sucediendo, quién constata lo que está sucediendo y cómo se transmite eso? Antes la tradición tenía un cierto sentido y había una posibilidad de intervención. Ahora se ha vuelto como un acto repetitivo y de dominio identitario. La tradición iba contra la historia porque la historia era de los poderosos. A veces, tengo la sensación de que hemos traicionado ese espacio idilico, porque del hecho de cuestionar la historia ha venido también el proceso inverso, en que por una cuestión científica se le hubiera otorgado el poder de la objetivación frente a lo tradicional polisémico.

Eso me recuerda un proyecto de la $55^{\mathrm{a}}$ Bienal ubicado justo a las afueras de uno de los lugares oficiales de la muestra: "The Museum of Everything". Este 
proyecto ponía de relevancia, precisamente, un tipo de arte extraoficial, no validado por los agentes legitimadores del sistema del arte.

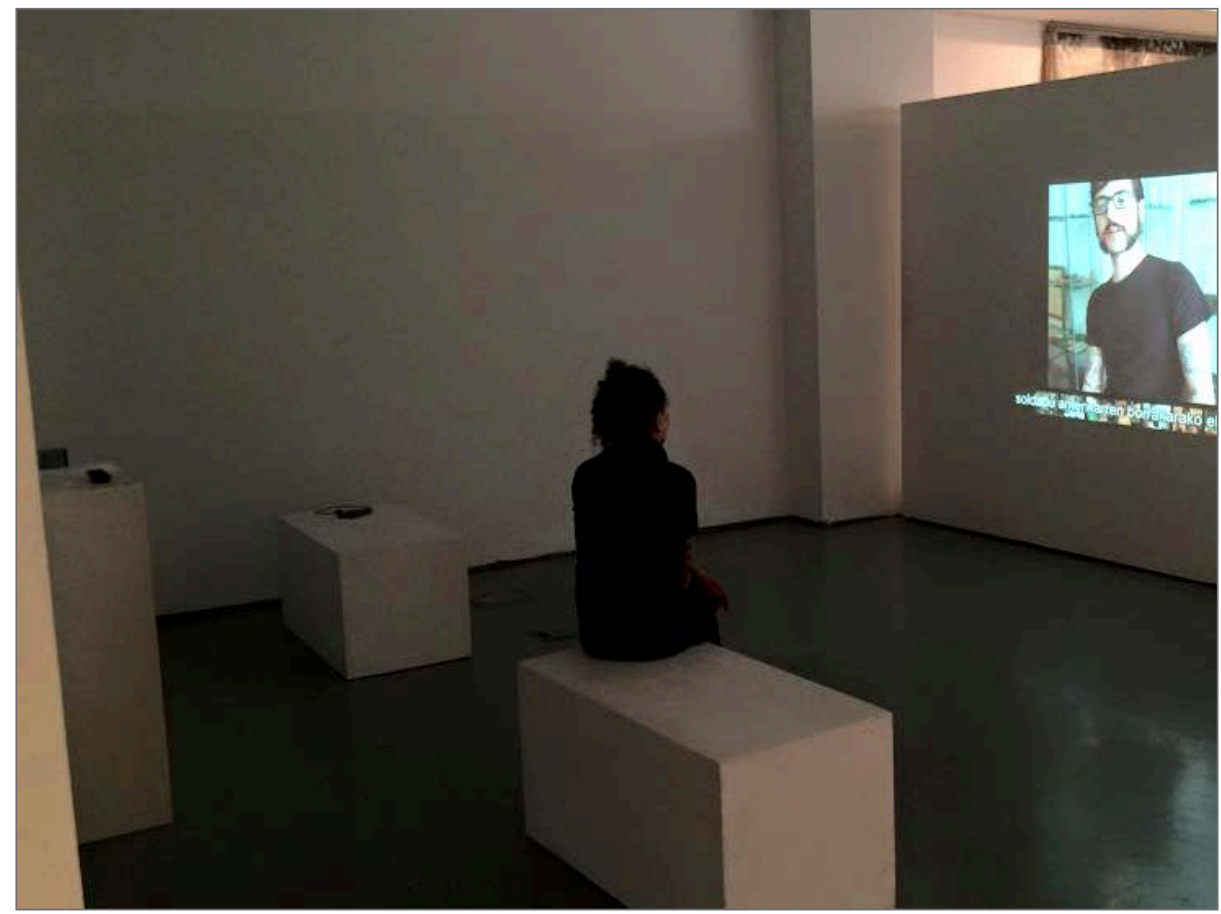

Imagen 2. EL DOCUMENTAL. Rafael Tormo Cuenca. Sala Portalea. Eibar, Marzo 2015

Precisamente en el texto de Hito Steyerl se desmonta todo ese entramado, quiénes eran los especialistas que hacían la traducción entre objetos. Eso era lo que ha sostenido un relato del mundo del arte, pero eso ha caído. El mensaje de Benjamin es que había que traducir cómo se relacionaban los objetos y ha sido en cierto modo el relato que ha mantenido el discurso del arte contemporáneo hasta el momento, el de los especialistas, los críticos que son los que dan validez y evalúan qué artistas, qué líneas de trabajo, etc. Y eso, sí que está anunciando que un cambio está próximo, o ya está aquí; y sí, se mantendrá un mundo del arte, el de la compra-venta, pero el arte irá por otro lado. Estaremos en otro sitio. 
Antes comentabas que las personas entrevistadas que están coleccionando objetos tienen un posicionamiento político, ¿en qué sentido?

Cada entrevista a los coleccionistas dura 3 o 4 minutos. En total son 37 minutos en los que se nos muestran las respuestas a estas preguntas: cómo se iniciaron en el coleccionismo; qué colecciones tienen; y en qué momento sintieron que aquello que había surgido de una necesidad individual y casi secreta tenía que expresarse desde un compartir con los demás. Este trabajo de lo que trata es, en definitiva, sobre cómo nos relacionamos con el mundo. Los objetos hasta hace un tiempo habían sido una parte esencial para poder leer el mundo, pero ese tipo de relación se ha roto. No solamente cae un sistema o una representación-una institución como la familia, la Iglesia o la monarquía-, es nuestra relación con los objetos lo que ha cambiado y por ende nuestro entorno. Repetimos las maneras que hemos tenido de relacionarnos con él hasta el momento. Por eso, el omitir que ninguno de los objetos de estos coleccionistas sea lo que se vea, sino que lo que prime sea la relación que ellos tienen con estos objetos y ellos sean considerados los objetos mismos; que recaiga sobre ellos el deseo.

Te interesa el video como herramienta artística más allá de la comunicación de ciertos contenidos. Desde el proceso artístico, ¿cómo ha intervenido su uso?

El proyecto tiene una forma de producción documental comprometida en transformar su propia representación formal. En definitiva, quiere contraponer aquel proceso relacional ante el de la verificación; aquello no significante, frente a aquello que significa; o una interpretación idealista frente al hecho de potenciar y experimentar la ausencia de parámetros y el abandono del conocimiento meritorio. Estos coleccionistas y sus colecciones nos hablan más de contenidos que de formas; de procesos afectivos y no de listas de valores. En consecuencia, dan un toque de atención "desfetichizado" para buscar otras formas de conexión que posibiliten el negativo de aquello que está por venir.

"Una imagen documental traduce el lenguaje de las cosas al lenguaje de los humanos. Por una parte, está firmemente anclada al reino de la realidad material. Por otra, también participa del lenguaje de los humanos, especialmente del lenguaje del juicio, el cual objetualiza la cosa en cuestión, fija su significado y construye categorías estables de conocimiento para su comprensión."

(Steyerl 2007, 2) 


\section{CUARTA PARTE. RECONSTRUYENDO ALGUNOS RELATOS EN TORNO AL ARTE}

Las voces van escuchándose aleatoriamente pero no se asocian a las imágenes que acompañan la instalación. No se comprende bien el mensaje. No se sabe muy bien qué está sucediendo. Esté o no el espectador, las ondas atraviesan el espacio. Parece que los altavoces dialoguen entre sí pero no alcanzan a establecer una conversación. El que mira esta orquesta desafinada tiene que variar el foco de atención ya que la voz va cambiando de sitio. Consulta las imágenes, pero sigue sin comprender.

La pieza sonora se compone de unas 32 grabaciones, de 1 a 3 minutos cada una. La voz, componente emocional fundamental, aparece como elemento plástico representado en ausencia del cuerpo, y aunque bastante desfigurada, estas grabaciones sin retoques gustaron especialmente al artista porque

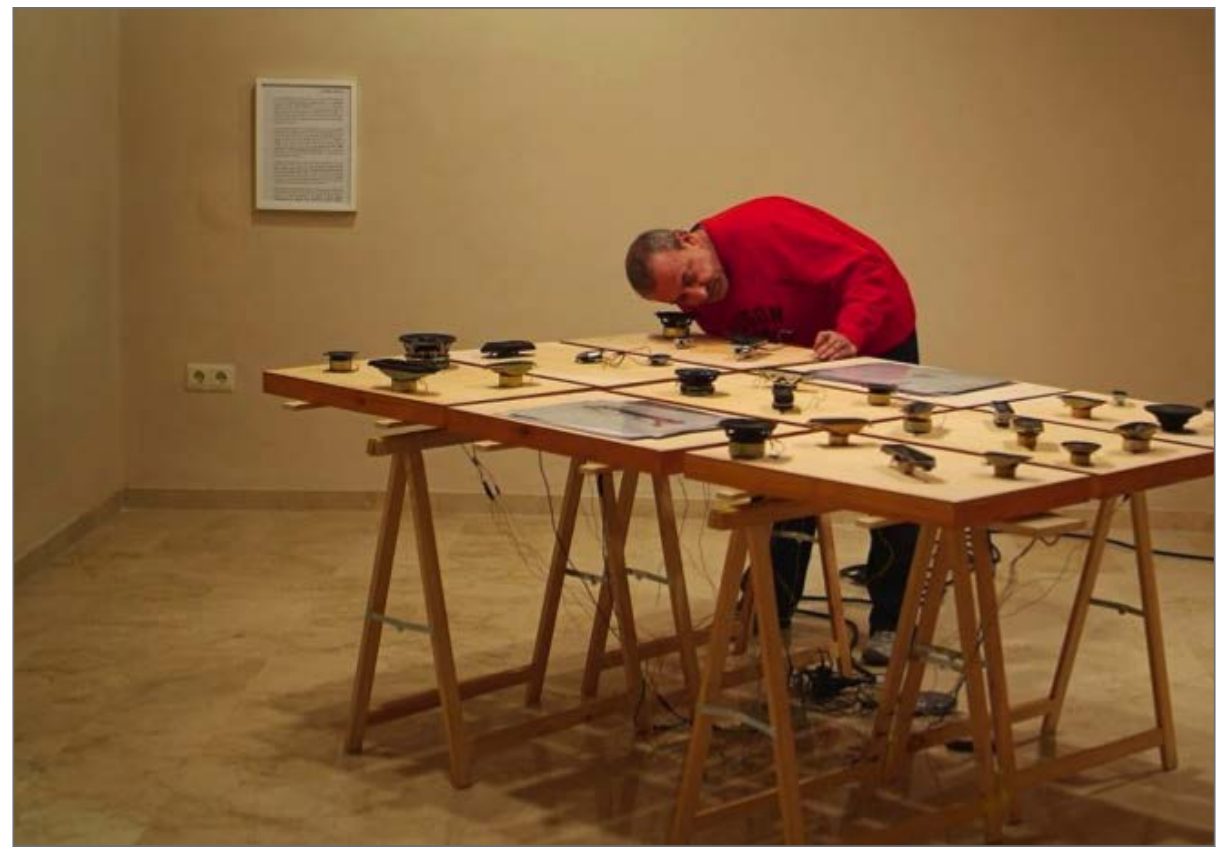

Imagen 3. LA PEÇA SONORA. Rafael Tormo Cuenca. Sala del Antiguo Ayuntamiento de Alberic. Valencia, Noviembre 2014 
había un punto complicado de lectura, "porque cuando lees, interpretas, cierras" decía.

"La traducción es profundamente política, ya que toca directamente cuestiones de poder en la formación del lenguaje. Concierne a la relación de los humanos con el mundo en general. Está relacionada con la emergencia (...). Es así como Benjamín relaciona directamente la traducción con el poder: observando la forma de la traducción, no su contenido. La forma de la traducción (...) será decisiva para que el lenguaje humano cree sujetos dominantes o subordinados, para que concuerde o no con las energías del mundo material"

(Steyerl 2006, 2).

Rafael Tormo Cuenca nos propone una mirada sobre un mundo que ha cambiado, atravesando el pensamiento contemporáneo para reflexionar sobre el sistema de poderes en el que nos encontramos inmersos y entender cómo nos hemos convertido en sujetos objetualizados, al tiempo que nos propone liberarnos. "Estado de sitio; gesto de coleccionar" abre toda una serie de interrogantes para poner en tela de juicio cuestiones que tomamos como irrefutables: por un lado, el propio concepto de Historia al revisar el papel de los especialistas; por otro lado, la idea de interpretación y traducción, cuestión que nos aleja del hecho en sí y nos subordina ante los expertos y sus narrativas dominantes.

Como conclusión y en definitiva interpretación, podemos aventurar que la obra de los libros fragmenta la imagen fotográfica de los coleccionistas convirtiéndolos en obra coleccionable; en el documental relatan sus motivaciones y preocupaciones en torno al acto de coleccionar para mostrar esta crisis de historia en la que nos encontramos, donde ya no es posible un eje dominante; y finalmente, la pieza sonora pone de manifiesto cómo ha cambiado nuestra relación interpersonal mediada por la tecnología y nuestra relación misma con los objetos a través del relato ininteligible de unos adolescentes.

\section{Referencias}

Benjamin, Walter (1927-1940) 2008. Obras. Libro I/vol. 2. Editado por Rolf Tiedemann; Schweppenhäuser, Hermann; traducido por Navarro Pérez, Jorge. Madrid: Abada

- (1927-1940) 2010. Obras. Libro IV / vol. 1. Editado por Rolf Tiedemann \& Hermann Schweppenhäuser, traducido por Jorge Navarro Pérez. Madrid: Abada 
- (1927-1940) 2013. Obras. Libro V/vol. 1. Obra de los pasajes. Editado por Rolf Tiedemann \& Hermann Schweppenhäuser, traducido por Juan Barja, Félix Duque \& Fernando Guerrero. Madrid: Abada

Canogar, Daniel. 1992. Ciudades efímeras: Exposiciones universales,espectáculo y tecnología. Editado por Julio Ollero. Madrid: Imaginario

García Calvo, Agustín. (1983) 2016. Historia contra tradición: Tradición contra Historia. $3^{a}$ ed. Madrid: Lucina

García Canclini, Néstor. 1987. "Ni folklórico ni masivo: ¿Qué es lo popular?” Diálogos de la Comunicación 17: 6-11. http://www.infoamerica.org/documentos_pdf/garcia_canclini1.pdf

Gielen, Pascal. (2008) 2014. El murmullo de la multitud artística: Arte global, política y posfordismo. Dirección por Darío Corbeira, traducido por Hugo López-Castrillo \& Alejandro Arozamena. Madrid: Brumaria

Gioni, Massimiliano. 2013. "Il Palazzo Enciclopedico [The Encyclopedic Palace]". En II Palazzo Enciclopedico, Short Guide, curated by Chris Wiley. Venezia: Fondazione La Biennale

Steyerl, Hito. 2006. "Hito Steyerl: El lenguaje de las cosas". Traducido por Marcelo Expósito. Transversal- EIPCP Multilingual Webjournal 6. http://eipcp.net/transversal/0606/steyerl/es 